\title{
Removal of methylene blue from textile waste water using kaolin and zeolite-x synthesized from Ethiopian kaolin
}

\author{
Zemedkun Mulushewa ${ }^{1}$, Wendimagegn Tagesse Dinbore ${ }^{1,2, *}$ (D) , Yihunie Ayele ${ }^{1}$ \\ ${ }^{1}$ Dilla University, College of Natural and Computational Science, Department of Chemistry, Dilla 419, Ethiopia, \\ ${ }^{2}$ Dilla University, University Industry linkage and Technology Transfer Directorate Office, Dilla 419, Ethiopia. \\ *Correspondence: Wendimagegnt@du.edu.et / tagesse99@gmail.com
}

Received: December 26, 2020 Accepted: March 11, 2021

\begin{abstract}
The wastewater generated from textile factories is linked to one of the main water pollution problems; therefore, it is important to reduce the pollutants in industrial effluents before their discharge into environment. The present study was to investigate the appropriateness zeolite- $x$ and kaolin as effective adsorbents for removal of methylene blue from the textile wastewater. Batch adsorption experiments were carried out to assess parameters that influence the adsorption process. The prepared zeolite-x and kaolin were characterized by Fourier Transform Infrared and X-ray diffraction techniques. The results of this study showed that the particle size is $40.77 \mathrm{~nm}$ and $0.45 \mathrm{~nm}$ kaolin and zeolite- $x$ respectively. The performance of zeolite-x adsorbent is best at the optimum $\mathrm{pH} 4$ with removal efficiency of $97.77 \%$ and kaolin adsorbent at $\mathrm{pH} 6$ with removal efficiency of $86.86 \%$. The optimum contact time was obtained at 60 and 80 minutes for zeolite- $x$ and kaolin respectively. While optimum adsorbent dosage was obtained at 0.4 and 0.6 grams with removal efficiency of $97.12 \%$ and $87.75 \%$ for the zeolite-x and kaolin adsorption experiment respectively. The confirmed square sum errors values are $1.0 \times 10^{-4}$ and $1.0 \times 10^{-3}$ for zeolite- $x$ and kaolin, respectively. The Adsorption isotherms results have well fitted to Freundlich isotherm than Langmuir isotherm. The adsorption kinetics results were best fitted the pseudo second order model. The result shows that the zeolite-x has high removal efficiency than kaolin at the same operating conditions. Application of this method can be economically, environmentally, and socially feasible to address wastewater problems. Further research has to be carried out on the removal capacity of this adsorbent for organic dyes not only from the textile industry but also from leather industries and soap industries.
\end{abstract}

Keywords: adsorption; kaolin; methylene blue; removal; textile wastewater; zeolite-x

\section{Introduction}

Environmental pollutants cause major problem worldwide. Natural water conservation is vital to protect the land and save the next generations. As discussed by Naghizadeh et al., [1] there are different types of industries such as textile, papermaking, cosmetics, food, and leather releasing wastewaters into the environment. Among these, the textile industry is one of the major industries in the country, largest water consumer and wastewater source. The wastewater generated from textile factories is linked to one of the main water pollution problems [2]. Wastewater of this industry includes chemicals, suspended solids, toxic compounds, and dyestuff, which are one of the most attention required wastewaters. The dyestuff and pigments are about 100,000 tons commercially available and over 700,000 tons produced annually across the world. It is estimated that $10-15 \%$ of the dye is lost during the dyeing process and released with the wastewater [3]. Arising as a result of the rapid development of textile industries, wastewaters containing dyes are directly or indirectly discharged into the environment as being on the increase, especially in developing countries. This contaminated water is very toxic to humans and animals [4].

Dyes are chemicals which on binding with the material will give color to them. Dyes are also categorized as nonionic and ionic (e.g., cationic (basic) and anionic (reactive, acid, direct) dyes) [5]. Methylene blue (MB) is a model cationic dye employed by industries such textile industry for a variety of purposes such as in coloring paper, dyeing cotton, wools, silk, leather, and coating for paper stock. MB can cause eye burn which may be responsible for permanent injury to the eyes of man as well as aquatic animals. It also has harmful effects, such as increase heartbeat, vomiting, diarrhea, irritation to the gastrointestinal tract with symptoms of nausea, shock, mental confusion if ingested in human. It also irritates the skin when in contact with it $[6,7]$. In general, cationic dyes, such as $\mathrm{MB}$, have higher toxicity levels than anionic dyes. As a result, the removal of $\mathrm{MB}$ from industrial effluents has become one of the major environmental concerns [8]. 
Multiples of chemical-physical methods are available, which are flocculation, coagulation, membrane filtration and surface adsorption are used for decolorizing textile wastewaters [5]. Conventional anaerobic wastewater treatment methods cannot remove dyes efficiently. The conventional treatment methods like electrodialysis, ion exchange, reverse osmosis, micro- and ultra-filtration, oxidation, and solvent extraction are expensive compared with adsorption [9]. Coagulation process produces large volume of sludge and needs higher sludge disposal costs, but ion-exchange process has not been adapted for a wide range of colors and costs. Although membrane process is effective in dyes separation, the related investment is relatively high, and the problem of membrane fouling is still a challenge. Adsorption is the most acceptable technique to reduce the concentration of dissolved dyes from aqueous solutions. Adsorption is a better option in terms of cost, simplicity of design and operation, availability, effectiveness, and lack of sensitivity to toxic substances compared with other methods. This technique is able to separate wide range of chemical compounds [10].

Zeolites are microporous, crystalline hydrated aluminosilicates $\left(\mathrm{A}_{1} \mathrm{O}_{4}\right.$ and $\left.\mathrm{SiO}_{4}\right)$ symmetrically stacked tetrahedral which result in an open and stable three-dimensional honeycomb structure with a negative charge. There are over 40 known natural zeolites and 160 synthetic zeolites have been documented. Synthetic zeolites have wider applications than natural zeolites due to their purity and also modification of the Si/Al ratio to suit a particular application. Zeolite-x is a synthetic counterpart of the naturally occurring mineral Faujasite and has one of the largest cavities and cavity entrances of any known zeolites [11].

In recent times, efforts have been made to obtain more cost-effective material as adsorbent in tertiary wastewater treatment. Kaolin (China clay) is a common low-cost natural clay and abundant adsorbent across the world, which was investigated as an adsorbent for the removal of dyes. In aqueous solution basic dyes yield colored cations, this could be captured on zeolite-x and kaolin by ion exchange. Its wide micropores make it useful for purification and the removal of dye from textile wastewater $[12,13]$. There is still little information on MB adsorption process utilizing zeolite-x adsorbent. Again, there are a few studies conducted on MB removal using kaolin as a capable adsorbent. However, using textile industrial effluent has not been evaluated by Ethiopian kaolin and zeolite-x synthesized from kaolin to removed MB. Therefore, it might be a good candidate for removing pollutants from wastewater and sewage. In this study, efficiency of kaolin and zeolite-x synthesized from kaolin as adsorbent to remove MB from textile wastewater was investigated.

\section{Materials and methods Materials}

The experimental study was conducted in a batch adsorption mode in which kaolin and zeolite-x were used as an adsorbent for the removal of MB from the textile industry, which is evaluated in a lab scale at the Dilla University chemistry research laboratory, Ethiopia. All the chemicals, reagents, and MB powders used were in analytical grade obtained from Sigma-Aldrich (Germany). MB was used as the adsorbate molecule in adsorption experiments (Figure 1). UV-Visible Spectrophotometer (NV 203) is used to measure the absorbance of MB. X-ray diffraction (XRD; Philips PW 1710 PANalytical; UK Ltd, Cambridge) and Fourier transformed-infrared spectrometry (FT-IR; Shimadzu IRAffinity-1 spectrometer; Japan) were used to characterization of adsorbent.

\section{Collection of raw kaolin and description of the sample study area}

Three kilograms of kaolin sample was collected from Hadiya Zone, lemmo Woreda, Belessa Kebele in SNNPR, Ethiopia. Belessa Kebele is located at a longitude of $37^{\circ} 58^{\prime} \mathrm{E}$ and latitude of $7^{\circ} 35^{\prime} \mathrm{N}$ in the region Southern People Nations and the Nationalities Regional State of Ethiopia as indicated in the sample was put into dry plastic bag and transported to Dilla University chemistry research laboratory and kept for use.

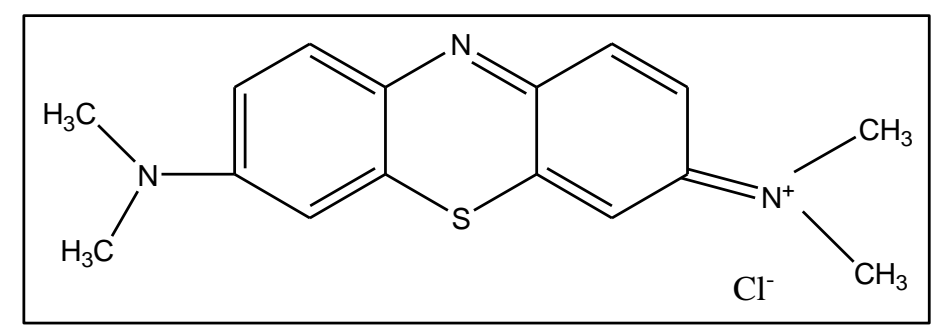

Figure 1. Molecular Structure of methylene blue (MB) 


\section{Pretreatment of kaolin sample}

The collected kaolin sample was grounded into powder using a mortar and pestle. It was sieved with a mesh size of $0.25 \mathrm{~mm}$ sieve under dry conditions and then washed with distilled water for several hours with constant stirring to remove any impurities and soluble inorganic salts. The samples were then left to settle, separated by decantation, and then dried in the open air until it gets dried. The kaolin adsorbent was put into dry plastic bag to prevent it from absorbing moisture until zeolite-x preparation and further studies [14].

\section{Synthesis of zeolite-x}

Zeolite-x was synthesized in the laboratory according to the method reported by Ma et al. [15] with some modifications. The pretreatment kaolin sample was calcined at a temperature of $900^{\circ} \mathrm{C}$ for 2 hours and it changed to metakaolin. The metakaolin needs to be delaminated with concentrated hydrochloric acid $(\mathrm{HCl})$ in the stoichiometric ratio of $20 \mathrm{~g}$ metakaolin with $15 \mathrm{~mL} \mathrm{HCl}$ and allowed to settle for 6 hours for dealumination and a solution was then treated in $250 \mathrm{~mL}$ conical flask using $1.5 \mathrm{M}$ sodium hydroxide $(\mathrm{NaOH})$ solution as active agents in the stoichiometric ratio. For $3 \mathrm{~g}$ metakaolin and $50 \mathrm{~mL} \mathrm{NaOH}$ in a heat resistant $250 \mathrm{~mL}$ volumetric flask was used and shake for 25 minutes at $270 \mathrm{rpm}$ in an orbital shaker for homogenizing then crystallize on a water bath at $50^{\circ} \mathrm{C}$ for 24 hours. Filter the crystal and washed with distilled water for several times. Then to develop the zeolite framework, it was put in an oven to dry at $65^{\circ} \mathrm{C}$ for 57 hours.

\section{Characterization of kaolin and zeolite-x}

To confirm the crystal structure and the composition of the synthesized zeolite and kaolin, it was essential to characterize the zeolite and kaolin. The XRD pattern of the zeolite-x which gives a measure of phase purity were recorded on Phillips PW $1710 X$-ray powder diffractometer over $2 \theta$ range of $6^{\circ}-50^{\circ}$. The diffractometer was equipped with a graphite monochromated $\mathrm{Cu} \mathrm{K} \alpha$ radiation source $(8.987 \mathrm{eV} ; \lambda=1.5418 \AA)$.

The vibrational properties were investigated by FT-IR. Measurements were done using 500 scans, units of log $(1 / \mathrm{T})$ (absorbance), over the IR region of $400-4,000 \mathrm{~cm}^{-1}$. An air background spectrum was collected at the start of the sample analysis. A small sample of zeolite and kaolin was centered on the zinc selenide ( $\mathrm{ZnSe}$ ) plate to ensure that it covered the entire crystal surface, and a pressure clamp was used to apply pressure on the sample. The zeolite and kaolin samples were analyzed three times. A background spectrum was measured before every sample to compensate for atmospheric conditions around the FT-IR instrument [11].

\section{Preparation of working standard solutions}

For this study MB powder obtained from Sigma-Aldrich (Germany) was used as the adsorbate molecule in adsorption experiments. Preparation of stock solution of MB was carried out by dissolving $1 \mathrm{~g}$ of MB in $1000 \mathrm{~mL}$ distilled water to get $1000 \mathrm{mg} / \mathrm{L}$. The intermediate solution of $100 \mathrm{mg} / \mathrm{L}$ of MB was prepared from the stock solution of $1000 \mathrm{mg} / \mathrm{L}$ by using dilution law. Further, 1, 5, 10, 15, and $20 \mathrm{mg} / \mathrm{L}$ of working standard solutions of MB were prepared from the intermediate dye solution by dilution. The working standard solution was prepared by adding real sample solution.

\section{Spectrophotometric determination of methylene blue (MB) in textile wastewater sample}

To determine concentration of MB in the textile wastewater, five series of standard MB solutions of $(1,5,10,15,20$ $\mathrm{mg} / \mathrm{L}$ ) were prepared by diluting the intermediate solution of MB with distilled water. Blank solution and working standards were run in UV-Vis Spectrophotometer at a maximum wavelength of $665 \mathrm{~nm}$ and five point's calibration curves were established. Then, textile wastewater sample solutions were taken to the UV-Vis spectrophotometer and direct readings of the sample absorbance were recorded and the concentration of the sample was calculated from the standard calibrated equation.

\section{Batch adsorption experiment}

Batch mode adsorption studies for individual parameters were carried out using $250 \mathrm{~mL}$ conical flask. The effects of different parameters such as $\mathrm{pH}$, contact time, adsorbent dose and adsorbate concentration were investigated by varying any one of the parameters and keeping the other parameters constant and study adsorption isotherms, adsorption kinetics to determine how the change in removal capacity induced by these factors. For each measurement, samples were periodically taken out of the flask then shake and filtered using a Whatman filter paper (India). The investigated ranges of the experimental variables were as follows: initial concentrations $(1,5,10,15$, and $20 \mathrm{mg} / \mathrm{L})$, pH of solutions $(2,4,6,8$, and $10)$, and adsorbent dosage $(0.04,0.2,0.4,0.6$, and $0.8 \mathrm{~g})$ and contact time $(20,40,60,80$, and 100 minutes). The absorbance of the filtrate solutions was determined using UV-visible Spectrophotometer at the maximum wavelength of $665 \mathrm{~nm}$ and it is possible to calculate the removal efficiency and capacity of kaolin and zeolite-x by using the Equation 1. [16].

Removal efficiency $(\%)=\frac{\mathrm{C}_{0-} \mathrm{C}_{\mathrm{e}}}{\mathrm{C}_{0}} \times 100$ 
Where $\mathrm{C}_{0}$ is the initial concentration $(\mathrm{mg} / \mathrm{L})$ and $\mathrm{C}_{\mathrm{e}}$ is residual (equilibrium) concentration $(\mathrm{mg} / \mathrm{L})$ of the MB being studied. The removal capacity of the kaolin and zeolite-x are the amount of $\mathrm{MB}$ adsorbed per unit mass of adsorbent was calculated based on the mass balance principle using Equation 2.

$$
\text { Removal capacity }\left(q_{e}\right)=\frac{\boldsymbol{C}_{o-} \boldsymbol{C}_{e}}{m} \times v
$$

Where $\mathrm{q}_{\mathrm{e}}$ is the removal capacity (mg of MB removed/g of adsorbents) , $\mathrm{V}$ is the volume of solution used (mL), and $\mathrm{m}$ is the mass of adsorbent used (g). [17, 18].

\section{Method validation (percent recovery)}

In order to evaluate the analytical applicability of the method, determination of MB in water samples. The validity of the optimized parameters was checked by adding the samples with a standard of known concentration of the analyte MB $(1 \mathrm{mg} / \mathrm{L})$ in to $12.5 \mathrm{~mL}$ of the textile wastewater sample. The recovery test can be calculated by using Equation 3.

$\mathrm{R}=\left(\frac{C_{\text {total }}-C_{\text {found }}}{C_{\text {added }}}\right) 100$

Where $\mathrm{C}_{\text {total }}, \mathrm{C}_{\text {found, }}$ and $\mathrm{C}_{\text {added }}$ are the concentrations of analyte after addition of known amount of standard in the real sample, the concentration of analyte in real sample and the concentration of known amount of standard which was mixed to the real sample, respectively.

\section{Adsorption isotherms}

Adsorption isotherms were investigated to evaluate the applicability of the adsorption process for the removal of MB from industrial wastewater. The interactions between the adsorbate and adsorbents were also be described by several models for the adsorption isotherms, based on a set of assumptions that are mainly related to the heterogeneity/homogeneity of adsorbents, the type of coverage and possibility of interaction between the adsorbate species. The most commonly used equilibrium models are Langmuir and Freundlich isotherms [19-21]. Therefore, adsorption isotherm experiments were conducted to examine the relationship between the solid phase and the solution phase concentration of the adsorbate at an equilibrium condition.

\section{Adsorption kinetic studies}

In order to investigate the adsorption rate processes, the most common models used to fit the kinetic adsorption experiments are pseudo-first-order model and pseudo-second-order model was used: The kinetics of adsorption describes the solute uptake rate, which in turn governs the residence time of adsorption reaction. It is one of the important characteristics in defining the efficiency of adsorption.

\section{Error analysis method}

Calculating a square sum of errors (SSE) values can determine which kinetic model appropriately explained the behavior of adsorbents and also decide which model is best fit for the particular system [22, 23].

\section{Results and discussion}

\section{Characterization using Fourier transform infrared (FT-IR) analysis}

The FT-IR spectrum of zeolite-x and kaolin (Figure 2) depicted the functional groups present on the zeolite-x and kaolin that could be responsible for the removal of MB from textile wastewater. FT-IR spectroscopy is used to probe the structure of zeolite-x and kaolin also monitor reactions in zeolite pores. Specifically, structural information can be obtained from the vibrational frequencies of the zeolite lattice observed in the range between $400 \mathrm{~cm}^{-1}$ and $1650 \mathrm{~cm}^{-1}$. The bands in the $3854 \mathrm{~cm}^{-1}$ correspond to the hydroxyl groups at the surface of the octahedral layers that interact with the oxygen atoms of the adjacent tetrahedral layers [24]. The FT-IR spectrum bands at $3692 \mathrm{~cm}^{-1}$ and $3650 \mathrm{~cm}^{-1}$ for kaolin and zeolite-x, respectively, correspond to the $\mathrm{OH}$ stretching vibrations of the surface and inner Al-OH groups of kaolinite [25, 26]. The

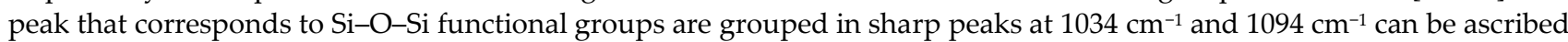
to the stretching vibrations of the Si-O-Si of kaolinite or quartz. The peak that corresponds to Si-O-Si groups is grouped in a single large band at $1094 \mathrm{~cm}^{-1}$ which also attributed to amorphous silica [27, 28]. A broad absorption bands at $3448 \mathrm{~cm}^{-1}$ and $3447 \mathrm{~cm}^{-1}$ indicating the presence of bonded $-\mathrm{O}-\mathrm{H}$ group or adsorbed water molecules in the kaolin and zeolite-x sample, respectively [29]. The presence of adsorbed water molecules is supported by the absorption band located at $1654 \mathrm{~cm}^{-1}$ commonly assigned to bending vibration of adsorbed water molecule [30]. Bands arising to stretching vibration mode of Si$\mathrm{O}-\mathrm{Al}$ is indicated by the presence of an absorption band at $542 \mathrm{~cm}^{-1}$ and the band at $1400 \mathrm{~cm}^{-1} \mathrm{C}=\mathrm{C}$ - bond stretch in aromatic compounds [27, 28]. Asymmetric and symmetric Si-O-Si stretching vibrations due to silica were present at $1034 \mathrm{~cm}^{-1}$ and 809 
$\mathrm{cm}^{-1}$, respectively [31]. The IR-spectral data of the synthesized zeolite double ring opening vibration $563 \mathrm{~cm}^{-1}$ in the FT-IR spectrum of the synthesized zeolite is near to $566 \mathrm{~cm}^{-1}$, which is a characteristic to faujasite [32]. The existence of functional groups $\mathrm{Si}, \mathrm{Al}$, and $\mathrm{O}$ observed in the spectrum, it was concluded that the formation of Zeolite framework was confirmed by FT-IR. The FT-IR spectrums of the prepared zeolite- $x$ and kaolin have well consistent with that of the reported in the literatures as indicated in Table 1.

\section{Characterization using X-Ray diffraction (XRD) analysis}

The amorphous nature of the zeolite- $x$ and the crystalline nature of kaolin were determined by using the intensity of the observed rays with respect to scattering angle $(2 \theta)$. The characteristic of broad peaks on the pattern of zeolite- $x$ at $2 \theta$ values $6^{\circ}, 11.94^{\circ}, 23.1^{\circ}, 25.54^{\circ}$ and $28.94^{\circ}$. Similar data was reported in the literature [11]. In addition, the peaks of kaolin at $2 \theta$ value of $12.38^{\circ}, 20.92^{\circ}, 26.72^{\circ}, 36.04^{\circ}$ and $38.54^{\circ}$ mostly shows crystal structure and less amorphousness structure when compared with zeolite-x structure. Similar findings have been previously reported by a literature [29].

The XRD patterns showed that the intense sharp peak at $2 \theta 26.72^{\circ}$ of kaolin indicating the presence of quartz and more crystal structure (Figure 3). The broad peaks found at around $25.54^{\circ}$ and $23.1^{\circ}$ for zeolite-x which confirms that the samples are amorphous or may have micro porous structure, which is considered as suitable for MB adsorption. During synthesized of zeolite- $x$ the concentrated hydrochloric acid was used. This is delaminated metakaolin as well as crystalline zeolite- $x$ change into amorphous. Therefore, adsorption capacity is enhanced because surface area to volume ratio increased. Previously, reported work is agreed with literature [35]. The XRD spectra were analyzed using Origin 6.0 software and the crystallite domain size was calculated from the width of the peaks, using Scherrer's formula [36].

According to the Scherer calculation, the synthesized zeolite-x grain size obtained was less than $2 \mathrm{~nm}(0.45 \mathrm{~nm})$ which is considered as micropores amorphous domain with greater number of adsorption sites and higher adsorption efficiency whereas the particle size of kaolin are in between 2-50 $\mathrm{nm}(40.77 \mathrm{~nm})$ considered as Mesoporous crystalline structure and less amorphousness structure with greater particle size, contain lower surface area this indicates that lower adsorption efficiency than zeolite-x. [37].

\section{Calibration curve for methylene blue (MB) standard solution}

The efficiency of adsorption is dependent on the solution $\mathrm{pH}$ because variation in $\mathrm{pH}$ leads to the variation in the degree of ionization of the adsorptive molecule and the surface properties of adsorbent. It is evident that both zeolite-x and kaolin were efficient in adsorbing the MB from textile wastewater solution. However, the synthesized zeolite-x showed higher removal efficiency than kaolin as shown in Figure 4. The results obtained in this study are in line with other articles [7, 38]. Higher percentage of adsorption is due to the electrostatic attraction between the negatively charged sites of the adsorbents and the positively charged MB dye molecules [39]. That is at the $\mathrm{pH} 4$ and $\mathrm{pH} 6$ for zeolite-x and kaolin respectively the negatively charged adsorbent sites increased which enhances the adsorption of positively charged $\mathrm{MB}$ cations through electrostatic force of attraction. Above this $\mathrm{pH}$, adsorption process slightly decreased due to weakening of electrostatic force of attraction between the oppositely charged adsorbate and adsorbent [40]. While at lower $\mathrm{pH}$ values less than 4 and 6 in the case of zeolite-x and kaolin respectively the number of negatively charged adsorbent sites decreased and the number of positively charged surface sites increased, which did not favor the adsorption of cationic MB dye due to the electrostatic force of repulsion. The results are in line with [41, 42].

Table 1. Comparison Fourier transformed infrared spectrometry (FT-IR) data of the synthesized zeolite-x and kaolin with literature value.

\begin{tabular}{|c|c|c|c|c|}
\hline \multirow{2}{*}{ Functional group } & \multicolumn{3}{|c|}{ FT-IR data $\left(\mathrm{cm}^{-1}\right)$} & \multirow{2}{*}{ Reference } \\
\hline & Kaolin & Zeolite-x & Literature & \\
\hline O-H stretching vibration & 3692 & 3854 & 3694 & {$[33]$} \\
\hline $\mathrm{O}-\mathrm{H}$ adsorbed water molecule & 3448 & 3447 & 3447 & [29] \\
\hline Al-OH stretching group of kaolinite & & 3650 & 3622 & {$[25,26]$} \\
\hline $\mathrm{H}_{2} \mathrm{O}$-adsorpition band & 1654 & & 1645 & [30] \\
\hline$-\mathrm{C}=\mathrm{C}-$ bond in aromatic compounds & 1400 & 1400 & 1430 & {$[28]$} \\
\hline Si-O-Si stretching & & 1094 & 1075 & {$[20]$} \\
\hline asymmetric Si-O-Si stretching & 1034 & & 1035 & {$[34]$} \\
\hline symmetric Si-O-Si stretching & & 809 & 797 & [34] \\
\hline Si-O-Al bond & 542 & & 536 & {$[27]$} \\
\hline
\end{tabular}


The calibration curve was obtained by preparing five MB solutions in different concentrations $(1 \mathrm{mg} / \mathrm{L}, 5 \mathrm{mg} / \mathrm{L}$, $10 \mathrm{mg} / \mathrm{L}, 15 \mathrm{mg} / \mathrm{L}$ and $20 \mathrm{mg} / \mathrm{L}$ ) mixed with wastewater sample, and plotted absorbance vs. concentration. The correlation coefficient of the calibration curve for MB standard solution clearly shows the calibration curves with good correlation coefficient. The results were found to be linear over the concentration range studied. The slope and the regression lines were similarly indicative of similar detector calibration sensitivity for analyte.

\section{Spectrophotometric determination of methylene blue (MB) in the real sample of textile wastewater}

The concentration of MB solution before and after adsorption was determined by measuring absorbance using UV-Visible spectrophotometer at the maximum wavelength of $665 \mathrm{~nm}$. The calibration equation, MB concentration before and after adsorption values were calculated from absorbance. The amount of adsorbed MB was measured at optimum conditions of pH 4 and 6, adsorbent dosage $0.4 \mathrm{~g}$ and $0.6 \mathrm{~g}$, contact time 60 and 80 minutes, and initial of MB concentration $1 \mathrm{mg} / \mathrm{L}$ using zeolite-x and kaolin, respectively.

\section{Adsorption experiments}

\section{Effect of $p H$ on the removal of methylene blue (MB)}

The effect of $\mathrm{pH}$ on the percentage of the MB removal is under at different values of $\mathrm{pH}$ ranging from (2-10) while keeping all the other parameters constant: contact time $(60 \mathrm{~min})$, dosage $(0.4 \mathrm{~g})$ and the initial metals concentration $(10 \mathrm{mg} / \mathrm{L})$. It has been seen that the percentage of MB removal was found to be high at the $\mathrm{pH}$ of $4(97.77 \%)$ in the case of zeolite-x adsorbent and the percentage removal of $\mathrm{MB}$ was high at $\mathrm{pH} 6(86.86 \%)$ in the case of kaolin adsorbent at fixed $\mathrm{MB}$ concentration $(10 \mathrm{mg} / \mathrm{L})$.

(a)

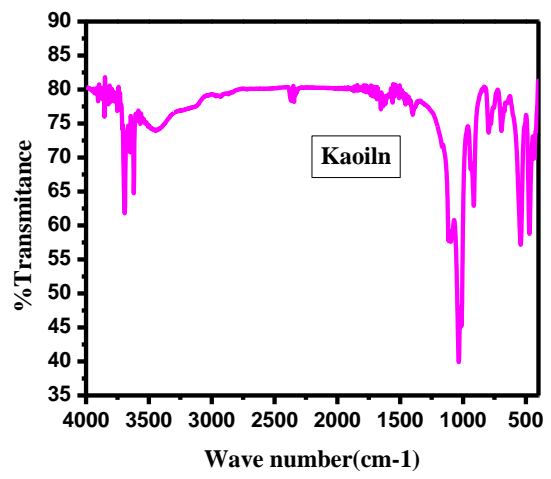

(b)

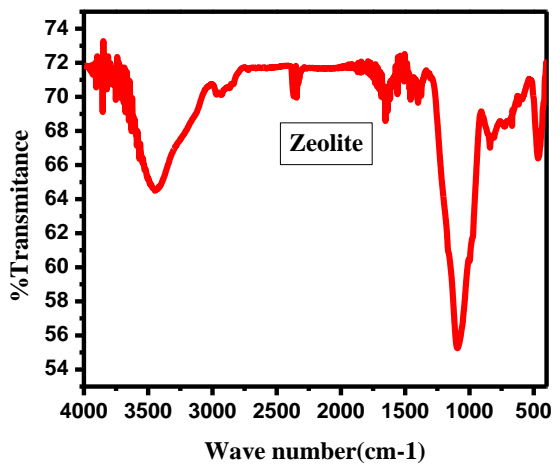

Figure 2 FT-IR spectra of (a) kaolin and (b) the synthesized zeolite-x

(a)

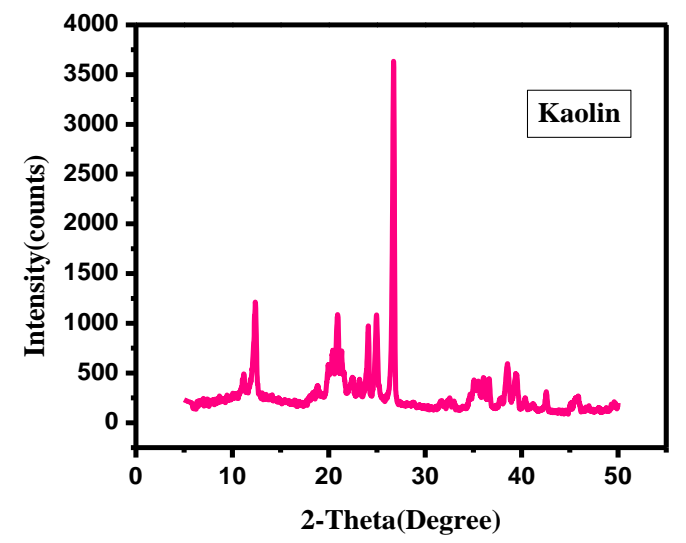

(b)

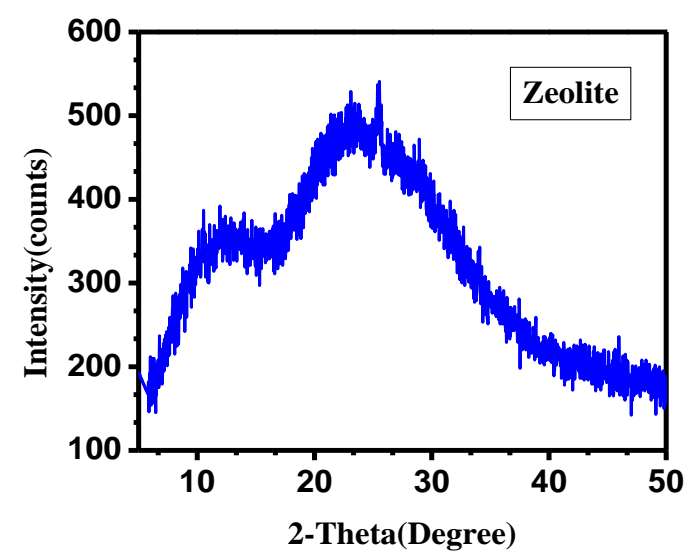

Figure 3. X-Ray diffraction (XRD) patterns of (a) kaolin and (b) the synthesized zeolite-X 


\section{Effect of contact time on the removal of methylene blue (MB)}

The effect of contact time on the removal of MB onto the zeolite- $x$ and kaolin at different experimental time is given in Figure 5. The rate of color removal of adsorbents was rapid up to optimum time and then after it proceeds at a slower rate and finally attains saturation after reaching to equilibrium. The rate of removal efficiency was higher in the beginning due to the large surface area of the adsorbents available for the adsorption of methylene blue. After a certain periods, only a very low increase in the MB removal was observed as there are few active sites on the surface of adsorbent which is consistent with the results obtained by $[17,43]$. From the contact time studied, it was found that 60 and 80 minutes for zeolite- $x$ and kaolin of agitation time are sufficient to reach equilibrium when $10 \mathrm{mg} / \mathrm{L}$ of $\mathrm{MB}$ concentration was employed. It is evident that both zeolite- $x$ and kaolin were best in adsorbing MB from textile wastewater solution. However, the synthesized zeolite-x higher removal efficiency than kaolin.

\section{Effect of adsorbent dosage on the removal of methylene blue (MB)}

Adsorbent dose is an important parameter in adsorption studies as it gives the optimum dosage at which maximum adsorption occurs. The effect of adsorbent dosage on the adsorption of MB is shown in Figure 6. It was observed that adsorption of MB increased with the increasing the adsorbent dosage. The reason behind is as the adsorbent dosage increases, the surface area of the adsorbent will increase and more adsorption sites were available to absorb the MB from the water sample and then attained a value at equilibrium [39]. In the zeolite-x experiment, $97.11 \%$ removal efficiency was observed at optimum adsorbent dosage of $0.4 \mathrm{~g}$ and kaolin adsorbent removed $87.75 \%$ of $\mathrm{MB}$ at optimum dosage of $0.6 \mathrm{~g}$ at fixed $\mathrm{MB}$ concentration $(10 \mathrm{mg} / \mathrm{L})$ containing $25 \mathrm{~mL}$ of solution.

(a)

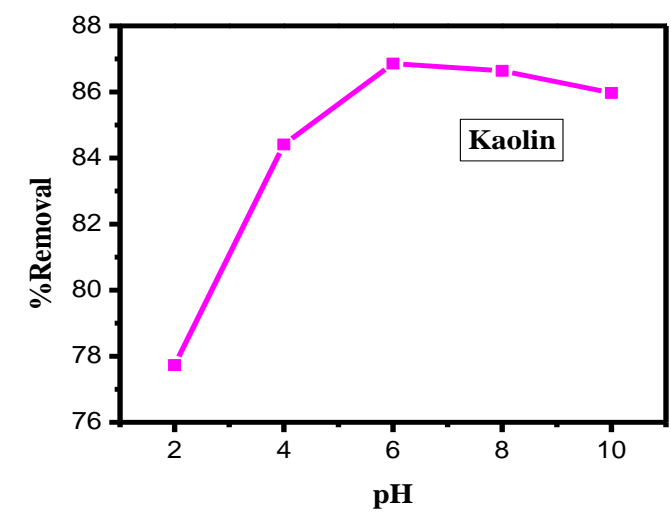

(b)

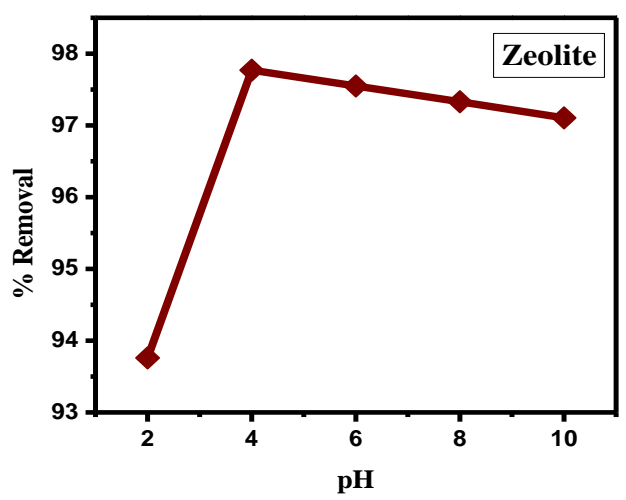

Figure 4. Effect of $\mathrm{pH}$ on the removal of methylene blue (MB) by (a) kaolin and (b) zeolite-x

(a)

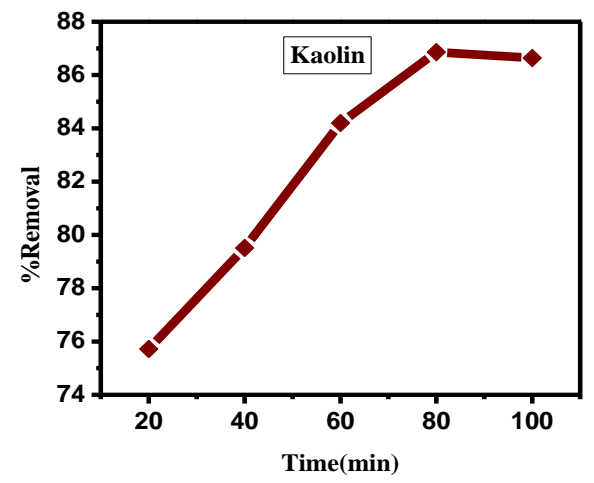

(b)

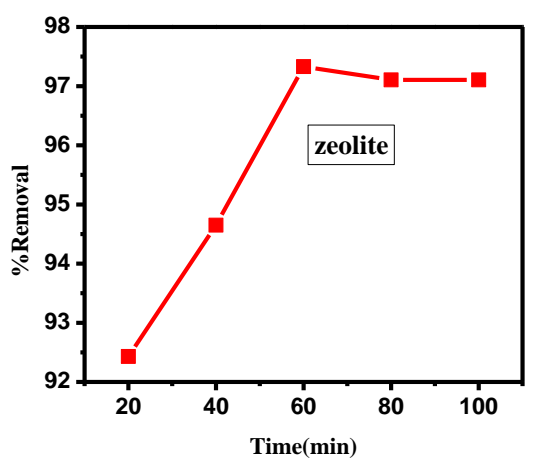

Figure 5. Effect of contact time on the removal of methylene blue (MB) by (a) kaolin and (b) zeolite-x 
(a)

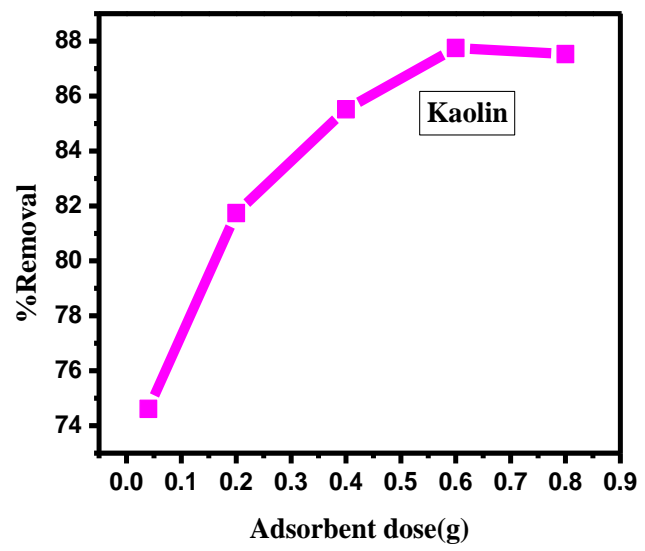

(b)

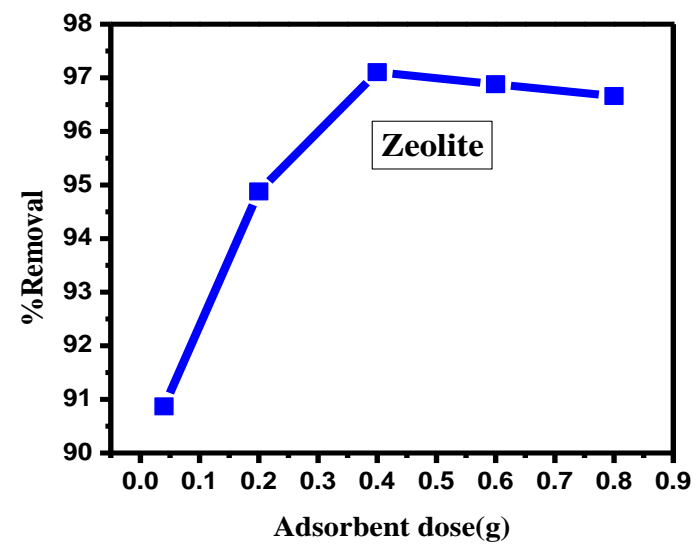

Figure 6. Effect of adsorbent dosage on the removal of methylene blue (MB) by (a) kaolin and (b) zeolite-x

\section{Effect of initial concentration on the removal of methylene blue (MB)}

The result shows that removal efficiency was decreased with increasing of initial concentrations, although the amount of total MB accumulation increased. From this experiment it was observed that about $97.77 \%$ and $86.64 \%$ of MB was removed at initial concentration of $1 \mathrm{mg} / \mathrm{L}$ by using zeolite-x and kaolin adsorbents respectively at same operating condition shown in (Figure 7). The percentage of MB removal decreases with an increase in the initial dye concentration, which may be due to the saturation of adsorption sites on the adsorbent surface. At a low initial concentration, there will be unoccupied active sites on the adsorbent surface, so most of the MB solution might contact active sites of adsorbents. However, at higher concentration most of the dye was not able to contact with the active surfaces because the active sites might have been occupied by the MB solution, which is consistent with the results obtained by [36, 44, 45].

\section{Method validation (percent recovery) Test for methylene blue (MB) in the textile wastewater}

Method validation is the process of providing that analytical method is acceptable for its intended purpose. The percentage recovery of the analyte was calculated and percentage recoveries for MB in water samples is $99.8 \%$, which are within the acceptable range $(100 \pm 10)$, obeys the Beer-Lambert law. This confirms that, the laboratory performance for the analyte is in control and the optimized procedure is valid. Therefore, the optimized adsorption was valid for water samples and is believed to remove MB from textile wastewater solution. Results of the recovery experiments shows the percentage recoveries for the MB $99.8 \%$ is within the acceptable range $(100 \pm 10 \%)$ verifying the validity of the method for MB analysis including the Spectrophotometric instrument and the standard solution of MB used for the determination of its concentration in the textile wastewater.

(a)

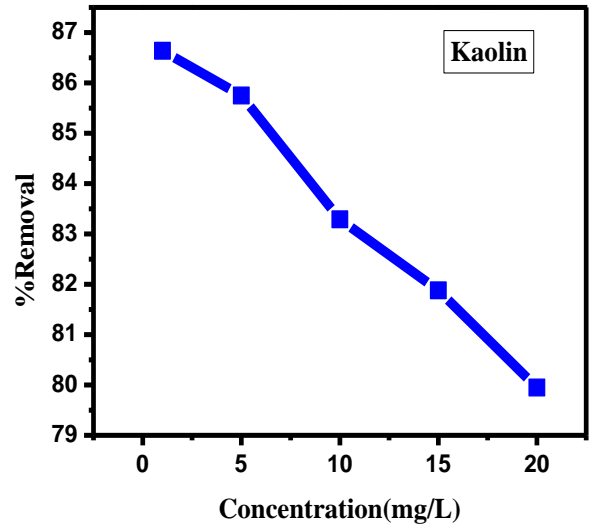

(b)

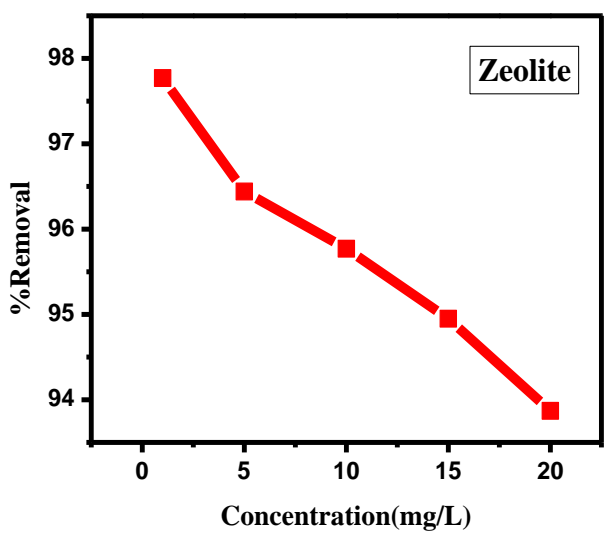

Figure 7. Effect of initial concentration on the removal of methylene blue (MB) by (a) kaolin and (b) zeolite-x 


\section{Adsorption isotherms \\ The Langmuir adsorption isotherm}

Langmuir adsorption isotherm is based on the formation of homogeneous monolayer coverage on the adsorbent surface, uniform energy of adsorption, and no interaction between molecules adsorbed on neighboring sites. The essential characteristics of the Langmuir equation can be expressed in terms of a dimensionless separation factor $\left(R_{L}\right)[33,45]$.

For working concentrations $1 \mathrm{mg} / \mathrm{L}, 5 \mathrm{mg} / \mathrm{L}, 10 \mathrm{mg} / \mathrm{L}, 15 \mathrm{mg} / \mathrm{L}$ and $20 \mathrm{mg} / \mathrm{L}$ the maximum adsorption capacity $(\mathrm{qm})$ were 1.93 and 1.65 for zeolite-x and kaolin, respectively, and the calculated energy of adsorption constant (KL) values is $1.18 \mathrm{~L} / \mathrm{mg}$ and $0.16642 \mathrm{~L} / \mathrm{mg}$ for zeolite-x and kaolin, respectively, indicated that the adsorption efficiency of the two adsorbents were good. According to the Langmuir model the $\mathrm{R}_{\mathrm{L}}$ values calculated as 0.04 and 0.23 were obtained between 0 and 1 for zeolite- $x$ and kaolin, respectively, which confirmed that the adsorbents adsorbing MB from textile wastewater is favorable under the conditions applied in this study. And the correlation coefficient $R^{2}=0.972$ and $R^{2}=0.995$ as indicated in for zeolite-x and kaolin, respectively, showed the linearity of the data and the Langmuir isotherm model fit the homogeneous nature of kaolin better than zeolite-x surfaces.

The Langmuir isotherm has also been used in the determination of the specific surface area. Since the Langmuir theory assumes monolayer coverage of the adsorbent's surface, the area can be calculated using physical constants. The specific surface areas of the two adsorbents were calculated. According to the results, zeolite- $x$ has the largest specific surface area $\left(7,146 \mathrm{~m}^{2} / \mathrm{g}\right)$, and it shows better adsorption capacity than kaolin with specific surface areas $\left(6,119 \mathrm{~m}^{2} / \mathrm{g}\right)$. These results are in agreement with previously reported data [48].

\section{The Freundlich adsorption isotherm}

Freundlich adsorption isotherm is based on the formation of heterogeneous surface or surfaces supporting sites of varied affinities, and it is assumed that the stronger binding sites are occupied first and that the binding strength decreases with increasing degree of site occupation. Freundlich isotherm model is the earliest known relationship describing the nonideal and reversible adsorption, not restricted to the formation of monolayer. This empirical model can be applied to multilayer adsorption, with non-uniform distribution of adsorption heat and affinities over the heterogeneous surface [47, 49].

A smaller value of Freundlich equation coefficient $1 / n$ points out a better adsorption mechanism and formation of relatively stronger bond between adsorbate and absorbent. If $1 / n<1$, bond energies increase with surface density, if $1 / n$ $>1$, bond energy decreases with surface density and if $1 / n=1$ all surface sites are equivalent. The $n$ values lying in the range of 1-10 for classification as favorable adsorption. [46].

In this study the calculated values of Freundlich equation coefficient $n$ ( $n=1.3$ for zeolite- $x$ and 1.2 for kaolin) was greater than 1, which indicating that the adsorption process is favorable. It is clearly seen that Freundlich model is better fit in the case of zeolite-x adsorption than Langmuir model since it has the higher value of $R^{2}=0.999$ in comparison with $R^{2}=$ 0.972. In addition, Freundlich model is better fit in the case of kaolin adsorption than Langmuir model since it has the higher value of $\mathrm{R}^{2}=0.998$ in comparison with $\mathrm{R}^{2}=0.995$ as indicated in and from the Freundlich constant $\left(\mathrm{K}_{\mathrm{F}}\right)$ values of zeolite- $\mathrm{x}$ better adsorption than kaolin this is because high value of $K_{F}$ shows that high adsorption 1.1 is greater than 0.22 . The values of the constants and calculated parameters of the isotherms showed in the Table 2.

\section{Adsorption kinetic studies Pseudo-first order kinetics}

The kinetics of MB adsorption onto zeolite-x and kaolin analyzed using pseudo-first order kinetic model. The conformity between experimental data (0.61) and the calculated value (0.08) shows disagreement therefore less favorable model for adsorption of $\mathrm{MB}$ onto the adsorbents as shown Table $3[7,21]$.

\section{The pseudo second-order kinetics}

The adsorption mechanism over a complete range of the contact time is explained by the pseudo-second order kinetic model. $\mathrm{R}^{2}$ value comes closer to unity in the case of the pseudo-second order kinetic model (0.999 and 0.995) which are higher than of the pseudo-first order kinetic model (0.97 and 0.98$)$ for zeolite-x and kaolin, respectively. From the result pseudo-second order kinetic model has the higher value of correlation coefficient confirms better fitting the experimental adsorption data than the pseudo-first order kinetic model as shown in Table 3.

\section{Error analysis value}

From SSE values the pseudo-second order kinetic has lower SSE value and it indicates that the adsorption process appropriately explain the behavior of both adsorbents better fit the pseudo-second order kinetic than pseudo-first order kinetic due to the fact that the lowest value of SSE is the best model for the particular system which is consistent with the 
Table 2. Langmuir and Freundlich isotherm for adsorption of MB onto zeolite-x and kaolin.

( $\mathrm{q}_{\mathrm{m}}$ : maximum adsorption capacity; $\mathrm{K}_{\mathrm{L}}$ : calculated energy of adsorption constant; $\mathrm{R}^{2}$ : correlation coefficient; $\mathrm{R}_{\mathrm{L}}$ : dimensionless separation factor; KF: Freundlich constant; n: Freundlich equation coefficient)

\begin{tabular}{cccccccc}
\hline & \multicolumn{2}{c}{ Zeolite $-\boldsymbol{X}$} & \multicolumn{2}{c}{ Kaolin } \\
\multicolumn{2}{c}{ Langmuir } & \multicolumn{2}{c}{ Freundlich } & \multicolumn{2}{c}{ Langmuir } & \multicolumn{2}{c}{ Freundlich } \\
\hline $\mathrm{q}_{\mathrm{m}}$ & 1.93 & $\mathrm{~K}$ & 1.1 & $\mathrm{q}$ & 1.65 & $\mathrm{~K} F$ & 0.22 \\
$\mathrm{~K}_{\mathrm{L}}$ & 1.2 & $\mathrm{n}$ & 1.3 & $\mathrm{~K}$ & 0.2 & $\mathrm{n}$ & 1.2 \\
$\mathrm{R}^{2}$ & 0.972 & $\mathrm{R}^{2}$ & 0.999 & $\mathrm{R}^{2}$ & 0.995 & $\mathrm{R}^{2}$ & 0.998 \\
$\mathrm{R}_{\mathrm{L}}$ & 0.04 & & & $\mathrm{R}$ & 0.23 & & \\
\hline
\end{tabular}

Table 3. Pseudo-first and second order kinetics for adsorption of methylene blue (MB) onto zeolite-x and kaolin.

\begin{tabular}{ccccc}
\hline & \multicolumn{2}{c}{ Zeoite-X } & \multicolumn{2}{c}{ Kaolin } \\
& Pseudo-first order & Pseudo-second order & Pseudo-first order & Pseudo-second order \\
\hline qe (experimental) & 0.61 & 0.61 & 0.54 & 0.54 \\
qe (calculated) & 0.08 & 0.62 & 0.3 & 0.57 \\
K & 0.04 & 1.23 & 0.05 & 0.4 \\
R $^{2}$ & 0.97 & 0.999 & 0.98 & 0.995 \\
SSE & 0.5 & $1.1 \times 10^{-4}$ & 0.14 & $1.2 \times 10^{-3}$ \\
\hline
\end{tabular}

results obtained by literatures [23, 42]. The obtained values of SSE from the experimental and calculated qe value of adsorption kinetics and the results also listed in Table 3.

\section{Conclusion and recommendation}

In this study, the use of the zeolite-x synthesized from Ethiopian kaolin as adsorbents for the removal of MB from textile wastewater has been studied. The structural properties of the adsorbents were analyzed by FT-IR and XRD techniques. The amounts of dyes adsorbed were found to vary with contact time, adsorbent dosage, $\mathrm{pH}$, and initial dye concentration. The study showed that both adsorbents are a good for MB removal from textile wastewater. However, when we compare the adsorbents, zeolite- $x$ is the best in removing MB from textile wastewater than kaolin. The maximum removal efficiency of the MB the zeolite-x and kaolin from solutions occurred at optimum condition of $\mathrm{pH} 4$ and 6, adsorbent dosage $0.4 \mathrm{~g}$ and $0.6 \mathrm{~g}$, contact time 60 and 80 minutes, and initial concentration $=1 \mathrm{mg} / \mathrm{L}$. The equilibrium adsorption data are best fitted by the Freundlich model as compared to Langmuir. Values of the equilibrium parameter RL from Langmuir isotherm and $n$ values from the Freundlich isotherm have indicated that the adsorption process is favorable. The kinetic of adsorbate-adsorbent interactions can be represented by the pseudo-second order model. The results demonstrated that the kaolin nanoparticle is a suitable precursor for the preparation of an adequate zeolite- $x$ for $\mathrm{MB}$ removal from textile industrial effluents. Kaolin and zeolite- $x$ is low cost and environment friendly for the removal of MB from textile wastewater. Further studies could be undertaken to improve the removal efficiency of the adsorbent by continuously optimizing additional parameters such as ionic strength effect, solvent selection, synthesis method, post-treatment method and different industries that may be the source of organic dye should be analyzed.

\section{Acknowledgement}

The authors are very thankful to office of the vice president for research and technology transfer of Dilla University (DU) for financial support for postgraduate fellowship program.

\section{Conflict of interest}

The authors declare no conflict of interest.

\section{CRediT author statement}

ZM: Conceptualization, Methodology, Software, Data curation, Writing- Original draft preparation, Investigation, WritingReviewing, and Editing; WT: Conceptualization, Methodology, Software, Supervision, Writing- Reviewing, Editing, Investigation; YA: Visualization, Supervision, and Editing. 


\section{ORCID}

Wendimagegn Tagesse Dinbore: 0000-0001-7466-5089

\section{References}

[1] Naghizadeh M, Ghafouria, Jafari A. Investigation of equilibrium, kinetics and thermodynamics of extracted chitin from shrimp shell in reactive blue 29 (RB-29) removals from aqueous solutions. Desalin Water Treat 2017;70:355-363. DOI: https://doi.org/10.5004/dwt.2017.20471

[2] Dalila B, Zoubir B, Othmane B, Boutoumi H, Hamitouche H, Aggoun A. Removal of methylene blue by adsorption onto Retama raetam plant: kinetics and equilibrium study. Chem J Mold Gen Ind Ecolog Chem 2016;11(2):74-83. DOI: http://dx.doi.org/10.19261/cjm.2016.11(2).10

[3] Naghizadeh A, Nabizadeh R. Removal of reactive blue 29 dye by adsorption on modified chitosan in the presence of hydrogen peroxide Environ Prot Eng 2016;42(1):149-168. DOI: https://doi.org10.5277/epe160112

[4] Yaseen A, Scholz M. Treatment of synthetic textile wastewater containing dye mixtures with microcosms. Environ Sci Poll Res 2018;25:1980-1997. DOI: https://doi.org/10.1007/s11356-017-0633-7

[5] Dehghan MH, Naghizadeh A, Rashidi A, Derakhshani E. Adsorption of reactive blue 29 dye from aqueous solution by multiwall carbon nanotubes. Desalin Water Treat 2013;51(40-42):7655-7662. DOI: 10.1080/19443994.2013.791772

[6] Velmurugan P, Rathina K, Dhinakaran G. Dye removal from aqueous solution using low cost adsorbent. Int J Environ Sci. 2011;1(7):1492-1503.

[7] Umoren S, Etim U, Israel A. Adsorption of methylene blue from industrial effluent using poly (vinyl alcohol). J Mater Environ Sci 2013;4(1):75-86.

[8] Abd M, Latif E, Amal M, Ibrahim M, Kady E. Adsorption equilibrium, kinetics and thermodynamics of methylene blue from aqueous solutions using biopolymer oak sawdust composite. J Am Sci 2010;6:267-283.

[9] Naghizadeha A, Ghasemia F, Derakhshania E, Shahabia H. Thermodynamic, kinetic and isotherm studies of sulfate removal from aqueous solutions by graphene and graphite nanoparticles. Desalin Water Treat 2017;80:247-254. DOI: https://doi.org/10.5004/dwt.2017.20891

[10] Mohammad K, Naghizadeh A. Montmorillonite nanoparticles in removal of textile dyes from aqueous solutions: Study of kinetics and thermodynamics. Iran J Chem Chem Eng 2017;36(6):127-137.

[11] Kwakye-Awuah B, Von-Kiti E, Nkrumah I, Ikyreve R, Radecka I, Williams C. Parametric, equilibrium, and kinetic study of the removal of salt ions from Ghanaian seawater by adsorption onto zeolite-x. Desalin Water Treat 2016;57(45):1-10. DOI: http://dx.doi.org/10.1080/19443994.2015.1128361

[12] Orjioke N. Synthesis and characterization of zeolite and its application in adsorption of Nickel from aqueous solution. [dissertation]. University of Nigeria; 2014 .

[13] Ibrahim M, Sayyadi A. Application of natural and modified zeolites in removing heavy metal cations from aqueous media: an overview of including parameters affecting the process. Int J Eng Sci 205;3:1-7.

[14] Ismael IS. Synthesis and characterization of zeolite-x obtained from kaolin for adsorption of Zn(II). Chin J Geochem 2010;29:130-136. DOI: https://doi.org/10.1007/s11631-010-0130-x

[15] Ma Y, Yan C, Alshameri A, Qiu X, Zhou C, Li D. Synthesis and characterization of 13X zeolite from low-grade natural kaolin. Adv Powder Technol 2013;25(2):495-499. DOI: http://dx.doi.org/10.1016/j.apt.2013.08.002

[16] Fereja WM, Dinbore WT, Benti G. Treatment of coffee processing wastewater using Moringa stenopetala seed powder: Removal of turbidity and chemical oxygen demand. Cogent Food Agric 2020;6(1):1-14. DOI: doi.org/10.1080/23311932.2020.1816420

[17] Million M, Belisti L. Removal of methylene blue dye from aqueous solution by bioadsorption onto untreated parthenium hystrophorous weeds. Mod Chem Appl 2014;2(4):1-5. DOI: https://doi.org/10.4172/2329-6798.1000146 
[18] Alouani M, Alehyen S, Achouri E, Taibi H. Removal of cationic dye methylene blue- from aqueous solution by adsorption on fly ash-based geopolymer. J Mater Environ Sci 2018;9(1):32-46.

[19] Neeraj J, Dwivedi M, Ashok W. Adsorption of methylene blue dye from industrial effluents using coal fly ash. Int J Adv Eng Res Sci 2016;3(4): 9-16.

[20] Elizabeth V. Synthesis and characterization of zeolites from bauxite and kaolin: application to the removal of heavy metals from mining wastewater. [Dissertation] Kabwe: Kwame Nkrumah University, Zambia; 2016

[21] Jamal O. Removal of methylene blue from industrial wastewater in pakestine using polysiloxane surface modified with biopyrazolic tripidal receptor. [Dissertation] Nablus: An-Najah National University, Palestine; 2015 (Palestinian).

[22] Markandeya S, Prasad S, Nitesh D, Mohan D. An efficient removal of disperses dye from wastewater using zeolite synthesized from cenospheres. J Hazard Tox Radioact Waste 2017;21(4):1-12.

[23] Mohamed E, Fatima A, Ragwan M, Ahmida K. Isotherm, kinetic and thermodynamic studies for the sorption of mercury (II) onto activated carbon from rosmarinus officinal's leaves. Am J Anal Chem 2015;6:1-10. DOI: 10.4236/ajac.2015.61001

[24] Rios A, Williams D, Roberts L. Removal of heavy metals from acid mine drainage using coal fly ash, natural clinker and synthetic zeolites. J Hazard Mater 2008;156(1-3):23-35. DOI: https://doi.org/10.1016/j.jhazmat.2007.11.123

[25] Lotfi M, Lazhar B, Jean C, Bouzaza A, Assadi A, Tirri A, et al. Removal of methylene blue from aqueous solutions by adsorption on Kaolin; Kinetic and equilibrium studies. Appl Clay Sci 2018;153:38-45. DOI: https://doi.org/10.1016/j.clay.2017.11.034

[26] Natiela C, Gabriela C, Sergio L, Dotto G, Mazutti M, Foletto E. Use of Brazilian kaolin as a Potential low-cost adsorbent for the removal of malachite green from colored effluents. Mater Res 2017;20:14-22. DOI: http://dx.doi.org/10.1590/19805373-mr-2016-0673

[27] Ali B, Kamel R. Improvement adsorption capacity of methylene blue onto modified Tamazert kaolin. Adsorpt Sci Technol 2017;35(9-10):753-773. DOI: https://doi.org/10.1177/0263617416684835

[28] Taju S. Synthesis of nano hydroxyapatite/ stilbite composite for defluoridation of drinking water. [dissertation] Addis Ababa University, Ethiopia; 2016.

[29] Weia G, Yanga L, Zhonga W, Li S. Fast removal of methylene blue from aqueous solution by adsorption onto poorly crystalline hydroxyapatite nanoparticles. J Nanomater Biostruct 2015;10(4):1343-1363.

[30] Pandiangan K, Arief S, Jamarun N, Simanjuntak W. Synthesis of Zeolite-X from Rice Husk silica and aluminum metal as a catalyst for transesterification of palm oil. J Mater Environ Sci 2017;8(5):1797-1802.

[31] A. Lijalem. Synthesis and characterization of zeolite from kaolin of Ethiopia, Studies of its application as detergent builder and in tannery wastewater treatment. [Dissertation] Addis Ababa University, Ethiopia; 2016

[32] Moneim MA, Ahmed EA. Synthesis of Faujasite from Egyptian clays: characterizations and removal of heavy metals". Geomater 2015;5(2):68-76. DOI: http://dx.doi.org/10.4236/gm.2015.52007

[33] Rios A, Williams D, Roberts L. Removal of heavy metals from acid mine drainage using coal fly ash, natural clinker and synthetic zeolites. J Hazard Mater 2008:156(1-3): 23-35, 2008. DOI: https://doi.org/10.1016/j.jhazmat.2007.11.123

[34] Aniela Z. Chemical modifications of hollow silica microspheres for the removal of organic pollutants in simulated wastewater. [Dissertation] Abdullah University of science and technology, Saudi Arabia; 2017.

[35] Soljic Z, Grba V. Study on the properties of synthetic zeolites A and X and amorphous aluminosilicate hydrates in relation to their application as adsorbents and as thin-layers in the acid medium. Bull Group Fr White Clay 2017;27(2):177-183. DOI: https://doi.org/10.3406/argil.1975.1245

[36] Auta M, Hameed B. Coalesced chitosan activated carbon composite for batch and fixed-bed adsorption of cationic and anionic dyes. J Colloid Surf B Biointerfaces 2013;105:199-206. DOI: 10.1016/j.colsurfb.2012.12.021

[37] Banks SW, Bridgwater AV. Catalytic fast pyrolysis for improved liquid quality, Processes and Technologies. Handbook of Biofuels Production (2nd Edition); 2016, 391-429. 
[38] Musstafa T, Yagub A. Removal of methylene blue contaminant by natural and modified low cost agricultural by product. [dissertation] Perth: Curtin University, Australia; 2013.

[39] Masresha B, Enyew A. Synthesis of magnetic nano composite adsorbent by co-precipitation method for wastewater treatment. Ethiop J Sci Sustain Dev 2017;4:33-48.

[40] Malik D, Jain C, Anuj K, Kothari. Removal of methylene blue dye in aqueous solution by agricultural waste. Int Resh J Eng Technol 2016;3:864-879.

[41] Vanianmai S, Subbarerddy Y, Nagaraja K, Jeyaraj B. Removal of methylene blue from aqueous solution by activated carbon of Vignamungo and paspalum scrobiculation: equilibrium, kinetics and thermodynamic studies. Ind J Chem Technol 2017;24(1):134- 144 .

[42] Zohre S, Ataallah S, Goharrizi k. Experimental study of methylene blue adsorption from aqueous solutions onto carbon nano tubes. Int J Water Resour Environ Eng 2010;2(2):16-28.

[43] Zahra D, Mohammad A, Mojdeh R, Faramarzian M. Adsorption of methylene blue dye from aqueous solutions by modified pumice stone: Kinetics and Equilibrium Studies. Health Scope 2013;2(3):136-144. DOI: 10.17795/jhealthscope12492

[44] Rahman M, Ruhul A, Alam AM. Removal of methylene blue from waste water using activated carbon prepared from Rice Husk. Dhaka Univ J Sci 2012;60(2):185-189.

[45] Nargish J. Development of dyes removal method from textile waste water" [dissertation] Dhaka: University of Dhaka, Bangladesh 2015.

[46] Mitiku T. Optimization and characterization of synthesis conditions of adsorbent from bone for removal of fluoride. [dissertation] Addis Ababa: Addis Ababa University, Ethiopia; 2015.

[47] Karti G, Mehta J. Removal of color from different dye wastewater by using Ferric Oxide as an adsorbent. J Eng Res Appl 2014;4:102-109.

[48] Alvaro D, Natalia J, David Y, Ortiz K. Comparative sorption of methylene blue onto hydrophobic clays. J Environ 2015;2(3):388-398.

[49] Meroufel B, Zenasn k. Adsorptive removal of anionic dye from aqueous solutions by Algerian kaolin: characteristics, isotherm, kinetic and thermodynamic studies. J Mater Environ Sci 2013;4(3):482-490. 